\title{
A Qualitative Study Exploring Women's Experiences of Unsafe Abortion in Sudan
}

\author{
Wafa Elamin1, Atif B. Fazari1,2,3, Khalifa Elmusharaf ${ }^{1,4}$ \\ ${ }^{1}$ Reproductive and Child Health Research Unit (RCRU), University of Medical Sciences \& Technology (UMST), Khartoum, Sudan \\ ${ }^{2}$ Omdurman Maternity Hospital, Ministry of Health, Khartoum, Sudan \\ ${ }^{3}$ Latifa Hospital Dubai Health Authority, Dubai, UAE \\ ${ }^{4}$ Graduate Entry Medical School, University of Limerick, Limerick, Ireland \\ Email: hyacinth.udah@griffithuni.edu.au
}

How to cite this paper: Elamin, W., Fazari, A.B. and Elmusharaf, K. (2017) A Qualitative Study Exploring Women's Experiences of Unsafe Abortion in Sudan. Open Journal of Social Sciences, 5, 149-158. https://doi.org/10.4236/jss.2017.53013

Received: January 25, 2017

Accepted: March 14, 2017

Published: March 17, 2017

Copyright (C) 2017 by authors and Scientific Research Publishing Inc. This work is licensed under the Creative Commons Attribution International License (CC BY 4.0).

http://creativecommons.org/licenses/by/4.0/

\section{(c) (i) Open Access}

\begin{abstract}
Background: Unsafe abortions contribute significantly to maternal morbidity and mortality. They are found more frequently in developing countries such as Sudan where abortion laws are restrictive and women have poor access to contraceptives. Gaps in the knowledge exist regarding women's decision making process to perform an unsafe abortion in Sudan. Understanding these factors is vital for planning and implementing family planning services. The aim of the research was to explore the experience of women exposed to an unsafe abortion in Khartoum-Sudan, and to address the underlying factors that affected women's decision to seek an unsafe abortion. Design: A descriptive qualitative approach was adopted using in-depth semi-structured interviews with women who had undergone unsafe abortions. Interviews were translated from Arabic; and data were analysed using a thematic approach. Setting and Participants: Participants were recruited from 2 settings: New Omdurman Hospital and Academy Teaching Hospital in Sudan. A convenience sample of women was used in the study. Results: Three core themes emerged: 1) There was an unbalanced relationship dynamic between women and their partners, which affected their use of contraceptives. 2) Maintaining secrecy of the unintended pregnancy and the unsafe abortion was paramount to all women for fear of social stigma. 3) Women tried to internalize and understand their negative experiences of unsafe abortion through religious context. Conclusion: Unsafe abortions have a significant impact on the quality of women's lives in Sudan. Open dialogue between men and women regarding family planning strategies; community education about the hazardous consequences of unsafe abortion as well as facilitating access to contraceptives and stressing their proper use are necessary steps to decrease the number of unsafe abortions in Sudan. More research is needed to fill the gaps in knowledge regarding unsafe abortions and sexual health among Sudanese women.
\end{abstract}




\section{Keywords}

Unsafe Abortion, Unwanted Pregnancy, Family Planning, Qualitative Research

\section{Background}

The WHO defines an unsafe abortion as "the termination of an unwanted pregnancy by persons lacking the necessary skills, or in an environment lacking minimal medical standards, or both" [1]. Unsafe abortions are thought to claim 47,000 lives annually and are found more frequently in developing countries with restrictive abortion laws and limited access to health care facilities [2]. Poor access to contraceptives is a documented cause of unintended pregnancy [3] and the high level of unintended pregnancies on a global scale highlight women's inability to make decisions within relationships on pregnancy-related intentions [4]. Socioeconomic concerns play a major role in the decision making process; poverty being a driving factor for termination of a pregnancy [5]. Unsafe abortions have also been linked to relationship problems with husbands or partners and directly to rape and sexual violence [6].

Sudan has an estimated Maternal Mortality rate of 311 deaths per 100,000 live births [7]. Unintended pregnancy rates are high and have been associated with low contraceptive use [8]. Laws only permit an induced abortion in cases of rape, incest or if the growing foetus will affect the mother's health [9]. Due in part to the illegality of abortions, the actual scale of unsafe abortions is unknown in Sudan. However in a survey of 726 patients seeking abortion-related care in 5 hospitals in Sudan; the results revealed that unintended pregnancy rates were very high [10]. In their study, Kinaro et al., (2009) identified that women sought unsafe abortions because they had inadequate access to health services, or poor knowledge of their human rights [10]. However, gaps in the knowledge still exist regarding the social and cultural factors that motivate women to perform an unsafe abortion.

Understanding these factors are vital for planning family planning services and raising awareness of the hazardous impact of unsafe abortion on women's lives. The aim of our research was to explore the experience of women exposed to an unsafe abortion in Khartoum-Sudan, and the underlying factors that affected women's decision to seek an unsafe abortion.

\section{Methods}

This exploratory study used descriptive qualitative methodology and participants were purposively sampled. The following inclusion criteria were used: women over 18 years; living in Sudan; and who had undergone an unsafe abortion. In the context of this study, an unsafe abortion was defined as the termination of an unwanted pregnancy, outside a hospital setting by persons lacking the necessary skills to do so. The study was reported against consolidated criteria for 
reporting qualitative research (COREQ) guidelines [11].

Semi-structured open-ended interviews were used to reconstruct the participants' experiences of unsafe abortions and facilitate exploration of the underlying driving factors. Interviews were conducted in private rooms in hospitals, due to the sensitive nature of the topic. The interview process was flexible, following a guide that was informed by both a review of the literature and after discussion between the authors. This study took place within Omdurman New hospital in Omdurman, Sudan and the Academy Charity teaching hospital in Khartoum, Sudan. These two hospitals were selected as they provide gynecological services to a large catchment population within Khartoum state. Women who were admitted for treatment of unsafe abortion complications were recruited into the study. Recruitment and interviews took place between November 2011 and March 2012.

Ethical approval was obtained from the University of Medical Sciences and Technology (UMST) as well as from both hospitals. Keeping with international standards, informed consent was taken from all participants. Verbal consent was taken without documentation due to the sensitivity of the topic being discussed and as participants wished to remain anonymous. However, participants were ensured that they could collaborate freely without the fear of being coerced. Women were also informed that they could withdraw from the study at any time. Participation was voluntary and no incentive was given.

Interviews lasted an average of 50 minutes and were handwritten as participants refused audio-recording, despite being reassured that they would not be reported to local authorities. Data were analyzed using inductive thematic analysis where codes and themes were generated from the data itself. All the interviews were translated from Arabic into English and transcribed. The transcribed material was manually coded and read repeatedly to allow for data immersion. Major themes were identified which formed a conceptual framework of women's experiences of unsafe abortion.

\section{Results}

A total of 10 women who fit the inclusion criteria were identified however only 7 women agreed to participate in the study. A summary of participant demographics are shown in Table 1 and a summary of the main themes and subthemes are shown in Table 2.

\subsection{Relationship Dynamics with Partners}

Women displayed varying degrees of affection towards their partners although they generally didn't describe the relationship in details. One participant said her relationship was "normal ... fine" (P2) while others described how "[my partner] used to tell me that I am beautifuP" (P4) or "He said he loved me" (P5). One woman highlighted how they had "a very long love story. We were engaged for over eight years, he always treated me like a queen even after we got married" (P1). Single participants (P4, P5, P6, P7) spoke more openly about their sexual 
Table 1. Participants demographic.

\begin{tabular}{cr}
\hline Demographic Characteristics & \\
\hline Age Groups & 5 \\
18 to 28 & 2 \\
29 to 39 & \\
\hline Employment Status & 4 \\
Employed & 3 \\
\hline Unemployed & 3 \\
\hline Marital Status & 4 \\
\hline Married & \\
\hline Single & 5 \\
\hline Location of Interview & 2 \\
\hline Academy hospital, Khartoum
\end{tabular}

Table 2. Summary of interpreted themes and sub-themes.

\begin{tabular}{cc}
\hline \multicolumn{1}{c}{ Theme } & Sub-theme \\
\hline Relationship dynamics with partners & Barriers to communication between couples \\
Inability to control family planning \\
Uaintaining secrecy was paramount \\
$\begin{array}{c}\text { Unplanned and unwanted Pregnancy } \\
\text { Coming to terms with the negative } \\
\text { experience of an unsafe abortion }\end{array}$
\end{tabular}

encounters with their lovers using phrases like "[he would] sleep with me" and "we have sex" frequently. One woman expressed deviating views regarding her relationship with her husband: "Now that we are married it is not like before. He changed after the honeymoon. He leaves me alone all the time ... He goes out with his friends all night. I want a divorce" (P3).

\section{Barriers to communication between couples}

Women alluded to barriers in communication with their partners and husbands (P1, P2, P3, and P4). This was a particular concern for married women who mentioned that "[he] never talks to me" (P3) while another woman echoed similar sentiments stating: "I can't tell him everything. He is much older than me and doesn't always understand what I am saying" (P1). This frustration was further aggravated by the inability to pursue a career outside the home: "He wouldn't let me work. I had to stay at home every day, staring at the walls. I got bored" (P3). Another respondent stated that:

"My husband told me before we got married; I was never to work outside the home. That was his condition and I agreed. But when things got difficult [financially], I worked in a primary school for a year. It didn't pay well and my husband wasn't happy so I stopped' (P1). 
While all single women were working at the time of their unsafe abortion; they too highlighted an unbalanced relationship dynamic (P4, P5, P6, and P7). They expressed frustration at being pressured regularly by their lovers to participate in sexual intercourse: "He kept asking me to sleep with him ... I said no many times but in the end, we did. It was my first time ... it hurt" (P4). One woman, who worked as a housemaid, received unwanted attention from her employer's son:

"In one of the houses I worked in there was a man who wouldn't leave me alone ... he took my telephone number and kept calling me. I was afraid his mother would find out. I told him not to call but he didn't stop ... One night I left his house after I finished work. It was dark, after Maghreb ... He started to walk behind me in the street.... He came from behind me and held me. I struggled to get away from him but he kept holding on. Then he tore his own clothing. He lifted my skirt up and he put me on the ground. He wasn't rough with me; he didn't hit me. He kept telling me that he loved me" (P5).

\section{Inability to control family planning}

Married women wanted to space their pregnancy but these wishes were met with refusal from their husbands, who had the final say on the matter: My husband wanted us to have a second child. I didn't want one so quickly... He wouldn't let me use the medication to stop the pregnancy" (P2). Women were concerned about re-living the pain of childbirth (P1, P2) and also expressed the desire to spend more time with their first born: It didn't feel fair for my first son, he wouldn't spend enough time with me if he had a brother" (P1).

The majority of participants (P1, P2, P4, P5, P6, P7) used only traditional methods of contraception to prevent pregnancy: "We avoid intercourse on certain days of the month (P1) and one woman explained how "If we did [have sex on those days] he wouldn't finish inside me" (P6). Only one woman used the contraceptive pills regularly (P3). Poor understanding of contraception was a recurrent theme:

"It all happened so fast, I didn't think I would have sex with him. I didn't think I could get pregnant ... it was the last thing on my mind so we never used any protection" (P4).

\subsection{Maintaining Secrecy Was Paramount}

\section{Unplanned and unwanted Pregnancy}

All women noticed that their menstrual period was late and guessed that they were pregnant: "I started vomiting in the early mornings. I felt sick all the time and then I noticed the bleeding was late. At first I didn't want to believe it but inside, I knew I was pregnant" (P4).

Participants were hesitant to immediately visit a doctor to confirm their pregnancy. They either opted to use a pregnancy kit obtained from a pharmacy (P2, P3, P6) or wait for two missed periods to be "sure" they were pregnant (P1, $\mathrm{P} 4, \mathrm{P} 5, \mathrm{P} 7)$. When asked why they refused to visit the doctor, one woman admitted that "I was too afraid to go to the doctor because then I would have to tell 
my husband" (P1) while another woman was worried her neighbors might find out as "the hospital was too near to my house" (P2).

When asked how they felt when they discovered they were pregnant, the majority of women said the news disappointed them: "I was very upset for many days after it" (P1). One participant had "cried and cried for hours" (P4) after hearing the news, while another said "I cried ... I didn't want the baby. I wanted him gone" (P5).

Choosing to have an unsafe abortion

All participants refused to tell their partners or family members about the pregnancy. Married women chose to deal with it alone. One woman searched online for ways to induce an abortion (P3) while others relied on stories they had heard from women in their community (P1, P2). To induce an abortion, they tried wearing "high heels", "Punching myself" or taking "a lot of malaria pills". One woman "started to exercise very hard, I made myself fall on the ground a few times and once I tried jumping out of a window. I even considered drinking henna but I was afraid to die" (P1). Another used a more invasive method by inserting a cannula into her uterus:

"After my husband left for work, I took my son to my mother's house so he wouldn't see what I was about to do ... I was also afraid that I might faint and not be able to take care of him" (P2).

In contrast to married participants, single women reached out to friends immediately to assist them in terminating the pregnancy. Their friends either performed the procedure themselves (P6, P7) or enlisted the help of a paid abortionist (P4, P5):

"I got pregnant a second time. I couldn't tell my mother again ... my friends told me they would bring it down for me. So they did. They put me on a bed and opened my legs. They inserted a metal wire and started scrapping inside me themselves ... my mother doesn't know about this. I don't want her to know" (P7).

For those who enlisted the help of abortionists, they paid large sums of money for the procedure, which was performed in their home (P4), at the abortionist's home (P5) or at a hospital (P3). Women noted how the abortionists worked "without asking questions" (P3). In all cases, abortionists inserted metal objects into the uterus to remove the gestational sac and terminate the pregnancy:

"I told the Sudanese woman I worked for about my problem. She said she has a friend that can help me kill the baby but that I would have to pay 300 Sudanese pounds. The money was a lot but I said yes. I would do it ... The woman came to my house with my friend... She used a metal to take the baby out. It was so painful, I was screaming and they told me not to scream. They were afraid the neighbours would hear me" (P4).

Dealing with the complications of Unsafe Abortion

The majority of women reported heavy bleeding following the unsafe abortion (P2, P3, P4, P5, P6, and P7): "When I woke up it was about an hour later. There 
was a lot blood on the bed. It was like the Vimto drink. I was shocked by the blood. I didn't know what [my friend] did to me, I didn't feel anything at first but then it started to hurt very much in my stomach" (P6).

Other consequences of the abortion included severe pain (P2, P4, P5, P6, P7) "fever" and "vomiting" (P4), "tiredness" (P6) and becoming "unconscious" (P7). Despite these symptoms, women did not rush to the hospital to seek assistance, waiting days before they finally decided to go. They experienced various medical complications following their unsafe abortion. Four women needed to undergo abdominal surgery (P2, P4, P6, P7) as they had ruptured their uterus. One woman had her uterus removed completely after failed attempts to repair the damage (P7) while another was discovered to still be pregnant despite the attempted abortion (P2).

\subsection{Coming to Terms with the Negative Experience of an Unsafe Abortion}

For all participants, the unsafe abortion was a painful experience both physically and emotionally. Participants believed that they were devoted Muslims and Christians and they mentioned "Allah" (P1, P6) or "God" (P4) on several occasions throughout the interview. They expressed religious guilt and one woman believed her pain and suffering was "punishment" for engaging in sexual intercourse outside marriage (P4). Another stated that "I know that Zeena (sex outside of wedlock) is haram... I only ask for Allah's forgiveness". "Regret" and "shame" were key words used by the majority of participants and this left women feeling "depressed all the time" (P2) or "ugly" (P4) when they remembered the abortion. For one woman her attempted unsafe abortion had not led to a loss of her pregnancy. Her son was alive and she mentioned:

"Now my son is seven years old. When I look at him and remember how hard I tried to lose him it breaks my heart. I don't want him or anyone else to ever know. Because I love him so much now" (P1).

All participants agreed that they couldn't tell their family members about the pregnancy or unsafe abortion as it would be too "dangerous" (P1). One woman was extremely frightened by the prospect of family members finding out saying:

"NO, no, no. I can't tell my family in Eritrea. They would kill me. Sex before marriage is not allowed in our religion. They would be very angry!" (P4).

All participants discussed the possibility of death; acknowledging that their lives had been in danger (P1, P2, P3, P4, P5, P6, P7). One woman commented " $I$ was very afraid. The doctors told me that what happened was very dangerous. Many women die because of it. I get scared when I heard them talk like this. That I might die" (P6). However; women were grateful that they had survived the ordeal: "I thank Jesus for saving me. I am so blessed" (P4).

\section{Discussion}

Three core themes emerged: 1) There was an unbalanced relationship dynamic between women and their partners, which affected their use of contraceptives. 2) 
Maintaining secrecy of the unintended pregnancy and the unsafe abortion was paramount to all women for fear of social stigma. 3) Women tried to internalize and understand their negative experiences of unsafe abortion through religious context.

Women in this study had little control over certain aspects of their lives such as pursuing a career or family planning. Their partners had the final say regarding both matters. Yet despite this, participants generally spoke tenderly about the love shared between the couple. There was very little indication that they wanted to change their relationship dynamic. Instead, women opted to clandestinely use an unsafe abortion as a form of family planning to space their pregnancies. This is not unlike other research, which suggests that unsafe abortions are used by women in Sudan as an alternative to contraception [10]. As married participants relied heavily on their husband for financial security, it could be suggested that they would not be able to secretly buy contraceptives without their husband's knowledge and therefore opted for an unsafe abortion. This possible link warrants further research. Access to contraceptives and their proper use is known to drastically reduce unintended pregnancies and therefore decrease the number of unsafe abortions [3] [12]. However, without partner's knowledge and acceptance of contraception these actions will remain futile.

Single women expressed concern about the frequent demand for sexual intimacy from their partners and they too had poor access to contraceptives or inadequate knowledge of its use. However, the main driving factor for performing an unsafe abortion was to hide the unlawful pregnancy from their families and the community. In all cases, women worried about their family's reaction to an unlawful pregnancy and the dangerous position it would put them in. Maintaining secrecy was paramount to all women within this study. Social stigma is known to play a major role in motivating women to perform an unsafe abortion. Studies show that there is a high value placed on honorable families within African communities and that the individual actions of each family member affect the social standing of the entire group [13]. Single women who indulge in unlawful sexual intimacy threaten not only their reputations but that of the entire family. For fear of their safety; women in this study went to great lengths to achieve an abortion and to conceal the complications that followed from their family and neighbors. While these findings align with other studies [5] [14], more research is required about women's value in society and the value placed on honorable families within Sudanese communities.

Participants were aware of the negative impact of the abortion on their lives and tried to understand and make sense of the ordeal. A link between "sin and punishment" was highlighted by both Muslim and Christian women. The ordeal was viewed as the price they had to pay for "Zeena" (unlawful sexual intercourse) or for attempting the abortion. This is not surprising considering the deeply conservative nature of the Sudanese community and the stigma associated with unlawful sexual intimacy. Previous research has shown that the psychological strain experienced by women after unsafe abortions may later manif- 
est as feelings of guilt and loss [15]. Women in this study alluded to feelings of guilt, regret and depression; blaming themselves for what had happened. However, there was no indication that they sought assistance to discuss these feelings or knew who to approach with this sensitive matter. What is promising however is that women did not suggest that they would refrain from sexual intimacy or lacked a desire to conceive again in the future.

This qualitative study is the first to describe the experiences of African women exposed to unsafe abortions in Sudan, as far as the authors are aware. One limitation is the relative small sample size. While this may limit the transferability of results we believe that this study nevertheless provides valuable insights about unsafe abortions within a Sudanese setting and offer guidelines for future policy recommendations.

\section{Conclusions and Recommendations}

Unsafe abortions have a significant impact on the quality of women's lives in Sudan. Taking into consideration the sensitive nature of this topic as well as the conservative nature of the Sudanese community, the following recommendations are suggested: Firstly, open dialogue between men and women regarding family planning strategies should be encouraged. Husbands and partners must be included in the discussion as their views will ultimately impact a woman's decision to have an unsafe abortion. Secondly, community members must be educated about the hazardous nature of unsafe abortions. Women are affected by the advice they receive from friends and the stories they hear from other women within their community. Thirdly, access to contraceptives should be available to both married and single women in Sudan along with adequate knowledge of their use, if we wish to decrease the number of lives lost to unsafe abortions. Finally, while this study has shed light on the motivating factors for performing an unsafe abortion, it has also revealed gaps in the body of knowledge regarding sexual health in Sudan. More research is needed to fill these gaps and offer solid basis for future policies.

\section{References}

[1] World Health Organization (2003) Safe Abortion: Technical and Policy Guidance for Health Systems. http://apps.who.int/iris/bitstream/10665/70914/1/9789241548434_eng.pdf

[2] Singh, S., Sedgh, G. and Hussain, R. (2010) Unintended Pregnancy: Worldwide Levels, Trends, and Outcomes. Studies in Family Planning, 41, 241-250. https://doi.org/10.1111/j.1728-4465.2010.00250.x

[3] Bankole, A., Singh, S. and Haas, T. (1998) Reasons Why Women Have Induced Abortions: Evidence from 27 Countries. International Family Planning Perspective, 24, 117-127. https://doi.org/10.2307/3038208

[4] Malarcher, S., Olson, L.G. and Hearst, N. (2010) Unintended Pregnancy and Pregnancy Outcome: Equity and Social Determinants. Equity, Social Determinants and Public Health Programmes, Chapter 10, 177-193.

http://cdrwww.who.int/social_determinants/tools/EquitySDandPH_eng.pdf\#page= $\underline{187}$ 
[5] Grimes, D.A., Benson, J., Singh, S., Romero, M., Ganatra, B., Okonofua, F.E. and Shah, I.H. (2006) Unsafe Abortion: The Preventable Pandemic. The Lancet, 368, 1908-1919. https://doi.org/10.1016/S0140-6736(06)69481-6

[6] Kaye, D.K., Mirembe, F.M., Bantebya, G., Johansson, A. and Ekstrom, A.M. (2006) Domestic Violence as Risk Factor for Unwanted Pregnancy and Induced Abortion in Mulago Hospital, Kampala, Uganda. Tropical Medicine \& International Health, 11, 90-101. https://doi.org/10.1111/j.1365-3156.2005.01531.x

[7] World Bank (2015) Maternal Mortality Ratio. http://data.worldbank.org/indicator/SH.STA.MMRT

[8] World Bank (2014) Contraceptive Use. http://data.worldbank.org/indicator/SP.DYN.CONU.ZS?locations=SD\&view=map

[9] Centre for Reproductive Rights (2008) The World's Abortion Laws. Centre for Reproductive Rights, New York. http://worldabortionlaws.com/

[10] Kinaro, J., Ali, T.E., Schlangen, R. and Mack, J. (2009) Unsafe Abortion and Abortion Care in Khartoum, Sudan. Reproductive Health Matters, 17, 71-77. https://doi.org/10.1016/S0968-8080(09)34476-6

[11] Tong, A., Sainsbury, P. and Craig, J. (2007) Consolidated Criteria for Reporting Qualitative Research (COREQ): A 32-Item Checklist for Interviews and Focus Groups. International Journal for Quality in Health Care, 19, 349-357. https://doi.org/10.1093/intqhc/mzm042

[12] Haddad, L.B. and Nour, N.M. (2009) Unsafe Abortion: Unnecessary Maternal Mortality. Reviews in Obstetrics and Gynecology, 2, 122-126.

[13] Mosquera, P.M., Manstead, A.S. and Fischer, A.H. (2002) Honor in the Mediterranean and Northern Europe. Journal of Cross-Cultural Psychology, 33, 16-36. https://doi.org/10.1177/0022022102033001002

[14] Johnson-Hanks, J. (2002) The Lesser Shame: Abortion among Educated Women in Southern Cameroon. Social Science \& Medicine, 55, 1337-1349. https://doi.org/10.1016/S0277-9536(01)00276-3

[15] Major, B. and Gramzow, R.H. (1999) Abortion as Stigma: Cognitive and Emotional Implications of Concealment. Journal of Personality and Social Psychology, 77, 735-745. https://doi.org/10.1037/0022-3514.77.4.735

Submit or recommend next manuscript to SCIRP and we will provide best service for you:

Accepting pre-submission inquiries through Email, Facebook, LinkedIn, Twitter, etc. A wide selection of journals (inclusive of 9 subjects, more than 200 journals) Providing 24-hour high-quality service User-friendly online submission system Fair and swift peer-review system Efficient typesetting and proofreading procedure Display of the result of downloads and visits, as well as the number of cited articles Maximum dissemination of your research work

Submit your manuscript at: http://papersubmission.scirp.org/ Or contact jss@scirp.org 